\title{
The Nature of the Stimulation of Fungal Growth by Potato Extract
}

\author{
By R. E. BEEVER* \\ Botany Department, University of Auckland, Auckland, New Zealand \\ AND E. G. BOLLARD \\ Plant Diseases Division, DSIR, Auckland, New Zealand \\ (Accepted for publication 8 November 1969)
}

\begin{abstract}
SUMMARY
Growth of four fungi on a medium of potato tuber extract and glucose was considerably higher than on a defined medium of glucose, asparagine, mineral salts, biotin and thiamine. Modification in turn of the carbon, nitrogen and growth factor components of the defined medium to resemble the extract medium did not indicate that any single component was responsible for growth stimulation; stimulation appeared to be due to the combined effects of all components. A synthetic medium of glucose, citric acid, amino acids, mineral salts and growth factors resembled the extract medium in composition and approached it in the ability to support growth of the test fungi.
\end{abstract}

\section{INTRODUCTION}

Marked responses to the inclusion of water extracts of potato tubers in growth media are obtained with many fungi, but little is known about the factors responsible. These responses are usually obtained despite differences in variety, maturity and conditions of growth of the tubers. Such extracts may supply both major and minor nutrients and different fungi may respond to different constituents or groups of constituents. In this study the effectiveness of a potato extract in stimulating growth of four plant pathogenic fungi was investigated.

\section{METHODS}

Organisms. Isolates of Diplodia pinea (Desm.) Kickx., Mycosphaerella melonis (Pass.) Chiu \& Walker, Peniophora sacrata G. H. Cunn. and a Rhizoctonia sp. were used. The fungi did not sporulate under the experimental conditions.

Preparation of potato extract. A single bulk aqueous extract of potato tubers (Solanum tuberosum var. Ilam Hardy) was used in all the work reported. The extract was prepared, at a final concentration of $400 \mathrm{~g}$. peeled tubers/1., as follows:

Tubers were peeled, minced into threequarters of the final quantity of water and boiled with constant stirring for $5 \mathrm{~min}$. The mixture was frozen at $-10^{\circ}$ overnight and, after thawing, was filtered through 'Miracloth' (Chicopee Mills, Inc., New Jersey, U.S.A.) in a basket centrifuge. The filtrate was stored in plastic bottles at

* Present address: Department of Genetics, The University of Leeds, Leeds, LS $29 \mathrm{JT}$. 
$-10^{\circ}$. When required, portions were thawed and filtered (Whatman no. 50 filter paper) to give a faintly opalescent extract.

Culture media. Compositions of the various media used are given in Table I. Medium $\mathrm{pH}$ was adjusted to $\mathrm{pH} 6.4$ (with $0.1 \mathrm{~N}-\mathrm{HCl}$ or $-\mathrm{KOH}$ ) before autoclaving ( $5 \mathrm{lb}$./in. ${ }^{2}$ for $30 \mathrm{~min}$.). Autoclaving was chosen as the method of sterilization as it is normal practice to sterilize potato extract media in this way. Three flasks of the autoclaved medium were mixed and the $\mathrm{pH}$ measured (initial $\mathrm{pH}$ ).

\section{Table I. Composition of media}

\section{Component and final concentration}

Glucose ro g./1.

Citric acid 0.5 g./l.

L-Asparagine $\mathrm{I} \cdot 06 \mathrm{~g} . / \mathrm{l}$. ( $8 \mathrm{~mm}$ )

L-Asparagine $0.26 \mathrm{~g} . / 1$. (2 $\mathrm{mm}$ )

$\mathrm{KNO}_{3} 2 \cdot 32$ g./1. (23 mM)

Amino acid mixture (I)

Inorganic salts (2)

Trace elements (3)

Thiamine (0.1 mg./l.)

Biotin (0.005 mg./l.)

Growth factor mixture (4)

Potato extract $500 \mathrm{ml}$./I.

\begin{tabular}{ccccc}
\multicolumn{5}{c}{ Medium } \\
A & B & C & D & E \\
$\times$ & $\times$ & $\times$ & $\times$ & $\times$ \\
- & - & $\times$ & - & - \\
- & $\times$ & - & - & - \\
- & - & - & $\times$ & - \\
- & - & - & - & $\times$ \\
- & - & $\times$ & - & - \\
- & $\times$ & $\times$ & $\times$ & $\times$ \\
- & $\times$ & $\times$ & $\times$ & $\times$ \\
- & $\times$ & $\times$ & $\times$ & - \\
- & $\times$ & - & $\times$ & - \\
$\times$ & - & $\times$ & - & -
\end{tabular}

(1) Amino acid mixture (mM concentration): L-Asn (2.75), L-Gin (I.75), 4-Aminobutyric acid (0.90), L-Arg (0.50), L-Val (0.50), L-Glu (0.40), L-Ala (0.25), L-Asp (0.25), L-Lys (0.25), L-Ile (0.20), L-Phe (0.20), L-Ser (0.15), Gly (0.10), L-Leu (0.10), L-Met (0.05), L-Pro (0.05), L-Thr (0.05).

(2) Inorganic salts (mM concentration): $\mathrm{K}_{2} \mathrm{HPO}_{4}(\mathrm{I}), \mathrm{K}_{2} \mathrm{SO}_{4}(\mathrm{I}), \mathrm{CaSO}_{4}(2), \mathrm{MgSO}_{4}$ (2).

(3) Trace elements (mg./l. final medium): $\mathrm{H}_{3} \mathrm{BO}_{4}(2 \cdot 86), \mathrm{MnCl}_{2} \cdot 4 \mathrm{H}_{2} \mathrm{O}$ (I·79), $\mathrm{ZnCl}_{2}(\mathrm{O} \cdot \mathrm{IO}), \mathrm{CuSO}_{4}$ $.5 \mathrm{H}_{2} \mathrm{O}(0.08),\left(\mathrm{NH}_{4}\right)_{6} \mathrm{Mo}_{7} \mathrm{O}_{24} \cdot 4 \mathrm{H}_{2} \mathrm{O}(0.04)$. Iron was added as the EDTA complex to give $3 \mathrm{mg}$. Fe/ 1. final medium.

(4) Growth factor mixture (mg./l. final medium): $p$-Aminobenzoic acid-K salt, (O.I), D-biotin $(0 \cdot 005)$, $i$-inositol (10), nicotinic acid (O.I), pantothenic acid-Ca salt $(\mathrm{O} \cdot \mathrm{I})$, pyridoxine $\mathrm{HCl}(\mathrm{O} \cdot \mathrm{I})$, riboflavin $(\mathrm{O} \cdot \mathrm{I})$.

Growth of fungi. Inoculations, except for the experiment of Table 2, were made with one wire loopful (loop diam. $5 \mathrm{~mm}$.) flask of a mycelial suspension prepared by homogenizing washed colonies in $10 \mathrm{ml}$. sterile glass-distilled water. For the experiment of Table 2 inoculum was pregrown on agar medium in Petri dishes and single plugs (diameter $2 \mathrm{~mm}$.) were inoculated into each flask. The fungi were grown in static culture in the dark at $25^{\circ}$ in $50 \mathrm{ml}$. Erlenmeyer flasks containing $10 \mathrm{ml}$. medium.

Fungi were harvested near the time of maximum dry weight yield on medium A (7 days for Diplodia pinea, Mycosphaerella melonis and Rhizoctonia sp.; 44 days for Peniophora sacrata) by filtering through preweighed glass gooch crucibles (porosity 3 ). The mycelium was washed three times with distilled water, dried at $105 \pm 5^{\circ}$ for $24 \mathrm{~h}$ and weighed. Yields are reported as the mean dry weight of mycelium/flask (three replicates). Filtrates from the three flasks were pooled and the $\mathrm{pH}$ measured (final $\mathrm{pH}$ ). Analytical methods. Unless otherwise stated analyses were carried out on autoclaved media. Total nitrogen was measured using a semi-micro Kjeldahl method without reduction before digestion because nitrate levels of the media analysed were low. Nitrate was measured by the method of Humphries (1956). Ammonium was estimated with ninhydrin (Yemm \& Cocking, 1955) following microdiffusion (Conway, 1957). 
Amino acids were estimated colorimetrically following separation by thin-layer electrophoresis and chromatography. The method used was essentially that of Bieleski \& Turner (1966). Organic acids were separated by the method of Cook \& Bieleski (1969) employing thin-layer electrophoresis and chromatography, except that sodium formate $(0.05 \%, \mathrm{w} / \mathrm{v})$ and bromophenol blue $(0.015 \%, \mathrm{w} / \mathrm{v})$ were added to the chromatographic solvent. Acids showed up as yellow spots on a blue background after drying in a cool air stream and were estimated approximately by visual comparison with standards.

Treatment of results. Means of yields have been compared using a form of the ' $t$-test' (Bailey, 1959). All tables present data from single experiments.

\section{RESULTS}

The extent of the responses to potato extract shown by the text fungi was measured in a preliminary experiment where growth on a glucose $/ \mathrm{KNO}_{3}$ medium was contrasted with growth on the same medium to which potato extract had been added (Table 2).

Table 2 Growth of test fungi on a glucose $/ \mathrm{KNO}_{3}$ medium with and without potato extract

Growth medium was medium E. Potato extract was added at a rate of $500 \mathrm{ml}$./1. Inoculum pregrown on potato dextrose agar (medium A+agar $\mathrm{I} 5 \mathrm{~g}$./1.). Yields are in $\mathrm{mg}$./flask.

\begin{tabular}{|c|c|c|c|c|}
\hline & \multicolumn{2}{|c|}{$\begin{array}{l}\text { Without potato extract } \\
\quad \text { (initial } \mathrm{pH} 4 \cdot 3 \text { ) }\end{array}$} & \multicolumn{2}{|c|}{$\begin{array}{l}\text { With potato extract } \\
\text { (initial } \mathrm{pH} 5.6 \text { ) }\end{array}$} \\
\hline & Yield & Final pH & Yield & Final $\mathrm{pH}$ \\
\hline D. pinea & 6 & $7 \cdot 9$ & $44(s)$ & $7 \cdot 5$ \\
\hline M. melonis & $3 I$ & $8 \cdot 2$ & $46(s)$ & $6 \cdot 3$ \\
\hline P. sacrata & 0 & $5 \cdot 3$ & $44(s)$ & $5 \cdot 2$ \\
\hline Rhizoctonia sp. & 17 & $7 \cdot 4$ & $46(s)$ & $6 \cdot 7$ \\
\hline
\end{tabular}

(s) Differs significantly $(P=0.01)$ from value without potato extract.

Following other preliminary work a standard potato extract medium (medium A) and a defined glucose/asparagine medium (medium B) were selected for further work. Asparagine, the sole nitrogen source in medium $B$, is known to be a major constituent of the soluble nitrogen fraction of potato tubers (Burton, I966) and to be used widely as a sole nitrogen source by fungi. Thiamine and biotin were included in medium B as these are the two growth factors most commonly required by fungi (Cochrane, I958). Growth on medium B was appreciable but for each fungus it was less than on medium A (Table 3). This difference in response to the two media was found to be independent of whether the inoculum was pregrown on a defined medium (medium D) or on potato extract medium (medium A).

Further work involved chemical estimations of certain components of potato extract, followed by attempts to modify the defined medium, medium B, so that it resembled the extract medium, medium $\mathrm{A}$, more closely both in composition and in ability to support the growth of the test organisms.

Carbon. The major carbon source in media A and B was the added glucose. Growth of the test fungi on a potato extract medium without added glucose was in all cases less than $25 \%$ of that with glucose. Further carbon compounds probably present in the 
extract medium include other sugars, probably some starch, amino acids and organic acids. Amino acids present are described later. Four organic acids were identified in the extract medium, medium A: citric acid ( 0.5 to I.0 g./1.), 2-pyrrolidone-5-carboxylic

Table 3. Growth of test fungi on a potato extract medium (medium A) and a glucose/asparagine medium (medium $B$ )

Inoculum pregrown for 12 days on medium $\mathrm{D}$. Yields in $\mathrm{mg}$./flask.

\begin{tabular}{|c|c|c|c|c|}
\hline & \multicolumn{2}{|c|}{$\begin{array}{c}\text { Medium A } \\
\text { (initial pH } 5 \cdot 4 \text { ) }\end{array}$} & \multicolumn{2}{|c|}{$\begin{array}{c}\text { Medium B } \\
\text { (initial pH } 5^{\circ} \text { ) }\end{array}$} \\
\hline & Yield & Final $\mathrm{pH}$ & Yield & Final pH \\
\hline D. pinea & 66 & $8 \cdot 3$ & $45(s)$ & $7 \cdot 4$ \\
\hline M. melonis & 60 & $8 \cdot I$ & $43(s)$ & $6 \cdot 5$ \\
\hline P. sacrata & $8 \mathrm{I}$ & $5 \cdot 8$ & $50(s)$ & $5 \cdot 4$ \\
\hline Rhizoctonia sp. & 79 & $8 \cdot 2$ & $63(s)$ & $4 \cdot 4$ \\
\hline
\end{tabular}

$(s)$ Differs significantly $(P=0.01)$ from value for Medium A.

Table 4. Growth of test fungi on a glucose/asparagine medium with and without citric acid

Growth medium was medium B. Citric acid was added at $\mathrm{I} \cdot 0 \mathrm{~g}$./l. Inoculum pregrown for Io days on medium $\mathrm{D}$. Yields are in mg./flask.

\begin{tabular}{|c|c|c|c|c|}
\hline & \multicolumn{2}{|c|}{$\begin{array}{l}\text { Without citric acid } \\
\text { (initial } \mathrm{pH} 5 \cdot 3 \text { ) }\end{array}$} & \multicolumn{2}{|c|}{$\begin{array}{l}\text { With citric acid } \\
\text { (initial pH } 6.0 \text { ) }\end{array}$} \\
\hline & Yield & Final pH & Yield & Final $\mathrm{pH}$ \\
\hline D. pinea & 35 & $7 \cdot 8$ & $45(s)$ & $8 \cdot 0$ \\
\hline M. melonis & 44 & $7 \cdot 8$ & $50(s)$ & $9 \cdot I$ \\
\hline P. sacrata & 50 & $6 \cdot 3$ & $57(n s)$ & $7 \cdot I$ \\
\hline Rhizoctonia sp. & 69 & 4.8 & $69(n s)$ & $8 \cdot 4$ \\
\hline
\end{tabular}

(s) Differs significantly $(P=0.0 \mathrm{I})$ from value for the left-hand treatment.

(ns) Not significantly different.

acid (0.25 to 0.5 g./1.), malic acid (trace) and succinic acid (trace). The 2-pyrrolidone-5carboxylic acid is probably largely produced from glutamine during autoclaving. Citric acid ( $1 \cdot 0 \mathrm{~g}$./1.) stimulated growth of Diplodia pinea and Mycosphaerella melonis when added to medium B (Table 4). Added at this level citric acid represents about $7.5 \%$ of the total carbon available in the medium. This alternative form of carbon may account for some of the observed stimulation but an indirect effect of citric acid on availability of metal ions or in influencing $\mathrm{pH}$ changes may also be important.

Nitrogen. Estimation of nitrogen components accounted for about $75 \%$ of the total nitrogen in the extract medium (Table 5). The only significant change apparent on autoclaving was the disappearence of glutamine presumably due to its conversion to ammonium and 2-pyrrolidone-5-carboxylic acid. Asparagine was present in medium B at $8 \mathrm{mM}(224 \mathrm{mg}$. $\mathrm{N} / 1$.). As the nitrogen in the extract medium (medium A) was $247 \mathrm{mg}$. N/1. the total nitrogen levels of both media were essentially the same. A number of reports, however, suggest that a mixture of amino acids may be a better nitrogen source for fungi than single amino acids (Nicholas, 1965; Harris, 1958). A mixture of amino acids of similar composition to those in the extract medium before autoclaving (note I, Table I) was therefore substituted for asparagine in medium B. The yields of the test fungi were, however, not significantly different from those on asparagine 
although the final $\mathrm{pH}$ values of the medium were all much less than that of the asparagine medium.

Mineral salts. Analysis of the mineral salts in the potato extract was not attempted. From analyses of potato tuber ash (Burton, 1966) and potato dextrose agar (Miller, I956) an estimate of the likely inorganic composition of medium A was made. Comparison of this with the mineral salts present in medium B suggested that differences were small and unlikely to be of significance for fungal growth. Although the extract medium (medium A) almost certainly contained elements not present in medium B none of these has been shown to be required by more than one or two fungi.

Table 5. Nitrogen compounds in a potato extract medium (medium A)

Analyses are means of at least two determinations (tr means less than I mg. N/1.).

\begin{tabular}{lcc}
\multicolumn{1}{c}{ Compound } & \multicolumn{2}{c}{ Quantity in medium (mg. N/l.) } \\
\cline { 2 - 3 } Nitrate & Non-autoclaved & Autoclaved \\
Ammonium & 16 & 16 \\
Asn & 6 & 17 \\
Arg & 66 & 72 \\
4-Aminobutyric acid & 26 & 24 \\
Lys & 13 & 16 \\
Glu & 6 & 6 \\
Val & 6 & 6 \\
Asp & 7 & 6 \\
Ala & 3 & 5 \\
Gln & 3 & 4 \\
Ser & 49 & 3 \\
Phe & 2 & 2 \\
Ile & 2 & 2 \\
Thr & 3 & 2 \\
Pro & tr & tr \\
Met & tr & tr \\
Tyr & tr & tr \\
Leu & tr & tr \\
Gly & tr & tr \\
Total of above components & tr & tr \\
Total nitrogen & 205 & 181 \\
& & 247
\end{tabular}

Growth factors. The growth factors in the extract medium were not measured. However, from published analyses (Burton, 1966) extracts from potato tubers may be expected to contain all the main fungal growth factors. The response of the test fungi, especially Peniophora sacrata, to added thiamine when grown on defined media (Table 6) confirmed that thiamine was probably present in the potato extract. By similar reasoning Milton \& Isaac (I967) concluded that biotin was present in potato extract.

To test whether other growth factors probably present in potato extract could stimulate fungal growth, a mixture of the commonly required growth factors (note 4, Table $\mathrm{I}$ ) was added to medium $\mathrm{B}$ at levels considered optimal for most deficient fungi (Cochrane, 1958). Despite the instability of some of these growth factors the medium was autoclaved as the growth response being studied was obtained with autoclaved media. None of the fungi showed any significant response. The independence of pregrowth conditions of the growth responses of media A or B supports the conclusion that no growth factor other than thiamine was involved in the responses of the test fungi. 
$A$ defined medium resembling potato extract medium. On the basis of the modifications described above a synthetic medium (medium $\mathrm{C}$ ) was designed as a defined substitute for potato extract medium (medium A). Growth of three of the test fungi on medium $\mathrm{C}$ was not significantly different from growth on medium A (Table 7). Growth of other fungus, Rhizoctonia sp., was significantly less. All fungi showed better growth on medium $\mathrm{C}$ than on medium $\mathrm{B}$.

Table 6. Growth of test fungi on a glucose/asparagine medium with and without thiamine

Growth medium was medium B. Inoculum pregrown for I I days on medium D minus thiamine and biotin. Yields are in $\mathrm{mg}$./flask.

\begin{tabular}{|c|c|c|c|c|}
\hline & \multicolumn{2}{|c|}{$\begin{array}{l}\text { Without thiamine } \\
\text { (initial } \mathrm{pH} 5 \cdot 2 \text { ) }\end{array}$} & \multicolumn{2}{|c|}{$\begin{array}{l}\text { With thiamine (o. I mg./1.) } \\
\text { (initial } \mathrm{pH} 5 \cdot 3 \text { ) }\end{array}$} \\
\hline & Yield & Final $\mathrm{pH}$ & Yield & Final pH \\
\hline D. pinea & 25 & $7 \cdot 3$ & $38(n s)$ & $7 \cdot 3$ \\
\hline M. melonis & 49 & $6 \cdot I$ & $47(n s)$ & $5 \cdot 3$ \\
\hline P. sacrata & 0 & $3 \cdot 9$ & $35(s)$ & $5 \cdot 4$ \\
\hline Rhizoctonia sp. & 21 & - & $66(s)$ & $4 \cdot 3$ \\
\hline
\end{tabular}

$(n s),(s)$-See Table 4 footnote.

Table 7. Growth of test fungi on a potato extract medium (medium A), a glucosel asparagine medium (medium $B$ ) and a defined substitute for potato extract medium (medium $C$ )

Growth media as described in Table I. Inoculum pregrown I4 days on medium A. Yields are in mg./flask.

\begin{tabular}{|c|c|c|c|c|c|c|}
\hline & \multicolumn{2}{|c|}{$\begin{array}{l}\text { Medium A } \\
\text { (initial pH } 5 \cdot 8 \text { ) }\end{array}$} & \multicolumn{2}{|c|}{$\begin{array}{c}\text { Medium } \mathrm{B} \\
\text { (initial pH } 5 \cdot 3 \text { ) }\end{array}$} & \multicolumn{2}{|c|}{$\begin{array}{c}\text { Medium C } \\
\text { (initial pH 5*9) }\end{array}$} \\
\hline & Yield & Final $\mathrm{pH}$ & Yield & Final pH & Yield & Final $\mathrm{pH}$ \\
\hline D. pinea & 60 & $7 \cdot 3$ & $38(s)$ & $7 \cdot 3$ & $54(n s)$ & $7 \cdot 3$ \\
\hline M. melonis & 57 & $7 \cdot 7$ & $46(s)$ & $5 \cdot 6$ & $50(n s)$ & 6.8 \\
\hline P. sacrata & 86 & $5 \cdot 6$ & $46(s)$ & $5 \cdot 5$ & $82(n s)$ & $5 \cdot 5$ \\
\hline Rhizoctonia sp. & 78 & $7 \cdot 8$ & $59(s)$ & $6 \cdot 2$ & $64(s)$ & $7 \cdot 4$ \\
\hline
\end{tabular}

(ns), (s)-See Table 4 footnote.

\section{DISCUSSION}

Growth of the four test fungi on potato extract and glucose (medium A) showed that potato extract supplies suitable sources and quantities of nitrogen, mineral salts, and growth factors. The good growth of fungi frequently observed on potato dextrose agar (medium A with agar) suggests that such stimulation is widespread.

Although the test fungi grew on the defined glucose/asparagine medium (medium B), in no case was growth as good as that on medium A. The experiments, where components of medium B were modified in turn to resemble the extract medium, indicated that this growth difference was not in general due to differences in carbon, nitrogen or growth factor sources. When, however, growth was tested on a medium incorporating such modifications simultaneously (medium C) all test fungi were found to grow better than on medium $B$ and in three cases growth was not different from that on medium A. This suggests that there was a synergistic effect on growth between components of medium $\mathrm{C}$. It would be interesting to compare growth of a wider range 
of fungi on this defined medium. Medium $\mathrm{C}$ resembles medium $\mathrm{A}$ chemically in the major carbon source (glucose,) in the presence of citric acid, in the organic nitrogen constituents and in the growth factors present. Also the $\mathrm{pH}$ changes in this medium during fungal growth were similar to those in medium A. Growth yields on medium $\mathrm{C}$ suggest that above a certain level the effect of potato extract in stimulating growth lies in a combination of a number of factors, which may be different for different fungi, rather than in any single factor.

We wish to acknowledge the assistance and advice of $\mathrm{Dr} \mathrm{A} . \mathrm{R}$. Ferguson, $\mathrm{Mr}$ N. A. Turner and Professor F. J. Newhook.

\section{REFERENCES}

BaILEY, N. T. J. (1959). Statistical Methods in Biology. London: The English Universities Press Ltd. Bieleski, R. L. \& TuRner, N. A. (1966). Separation and estimation of amino acids in crude plant extracts by thin-layer electrophoresis and chromatography. Analytical Biochemistry 17, 278.

Burton, W. G. (1966). The Potato. 2nd ed. Wageningen: H. Veenman and Zonen N.V.

Cochrane, V. W. (1958). Physiology of Fungi. New York: John Wiley and Sons, Inc.

Conway, E. J. (1957). Microdiffusion Analysis and Volumetric Error. 4th ed. London: Crosby Lockwood and Son Ltd.

Cook, A. R. \& BIELESKI, R. L. (I969). Fractionation of plant extracts by thin-layer electrophoretic and chromatographic techniques. Analytical Biochemistry 28, 428.

HARris, G. (1958). Nitrogen metabolism. In The Chemistry and Biology of Yeasts. Ed. by A. H. Cook, p. 437. New York: Academic Press.

HuMPHRIES, E. C. (1956). Mineral components and ash analysis. In Modern Methods of Plant Analysis. Ed. by K. Paech and M. V. Tracey, vol. I, p 468. Berlin: Springer-Verlag.

MilleR, P. M. (I956). Spectographic analysis of water agar, potato-dextrose agar and V-8 juice agar. Phytopathology 46, 526.

Milton, J. M. \& IsAaC, I. (I967). Studies on a biotin requiring strain of Verticillium dahliae. Transactions of the British Mycological Society 50, 539.

Nicholas, D. J. D. (1965). Utilization of inorganic nitrogen compounds and amino acids by fungi. In The Fungi. Ed. by G. C. Ainsworth and A. S. Sussman, vol. I, p 349. New York and London: Academic Press.

Yemm, W. E. \& CockING, E. C. (1955). The determination of amino acids with ninhydrin. Analyst, London 80, 209. 